\title{
Melting of Titanium and Its Alloys Using a Plasma Progressive Casting Furnace
}

\author{
Hiroyuki YAMADA, Kouji YOSHIDA, Suguru NAKAYAMA ${ }^{1)}$ and Tsukasa NISHIMURA ${ }^{1)}$
}

Research and Development Division, Daido Steel Co., Ltd., Daido-cho, Minami-ku, Nagoya, Aichi-ken, 457 Japan. 1) Hoshizaki Plant, Daido Steel Co., Ltd., Daido-cho, Minami-ku, Nagoya, Aichi-ken, 457 Japan.

(Received on December 6, 1991; accepted in final form on May 22, 1992)

A PPC (Plasma Progressive Casting) furnace with a water cooled mold and plural plasma torches was constructed to melt titanium and its alloys. Ingots of titanium and its alloys have been satisfactorily produced and satisfied chemical compositions and mehanical properties required for VAR double melted ingot.

This process has a distinctive advantage of efficient utilization of titanium and titanium alloys scrap.

KEY WORDS: PPC; Ti; plasma; tungsten; helium.

\section{Introduction}

Compared to the characteristics of engineering steels, titanium is lighter in its specific weight and higher in its strength and superior in its anti-corrosive characteristic. Therefore titanium is used not only for the parts of aircraft, atomic generators and chemical plants but currently also for automobile parts.

Titanium is a quite active element and has strong affinity to oxygen and nitrogen. In consequence it is dispensable to be melted under vacuum or inert atmosphere, and in a water cooled mold.

As a commerical production process, consumable electrode remelting process (VAR) has been the most common practice and this still remains as the major production process. In this process steps to form blocks of sponge titanium by a forging press, welding them into a long electrode, and repetition of vacuum arc remelting are involved, and so rather complex and big scale of equipments are required. A weak point of the process is to have a limitation to the use of titanium scrap, which is a cheap source of raw material and those amount of circulation in the market is increasing.

Since 1955, the application of plasma arc melts and refines metals has been studied in Daido Steel Co., Ltd. In 1972 we started the development of Plasma Progressing Casting furnace (hereinafter it is called as PPC) as a melting furnace of titanium, which is very active element. The test was started by a $25 \mathrm{~kg}$ furnace and later on in 1978 it was scaled up to a $50 \mathrm{~kg}$ furnace of 3 torches. Through the study in this period, feasibility of it as a titanium melting device and the quality had been recognized. Furthermore the use of plural torches was feasible and together with the rotation of the torches and the application of electro magnetic stirring in the mold, which assured homogeneous melting, the possibility of further scale up of the furnace has been confirmed.

Based on those results, in 1983 a commercial production 2 ton PPC was built at Hoshizaki Plant of Daido Steel. Since the time, titanium ingots have been satisfactorily produced by the PPC-VAR process and the percentage of scrap used among raw materials has been increasing. Outline of PPC-VAR process of Daido

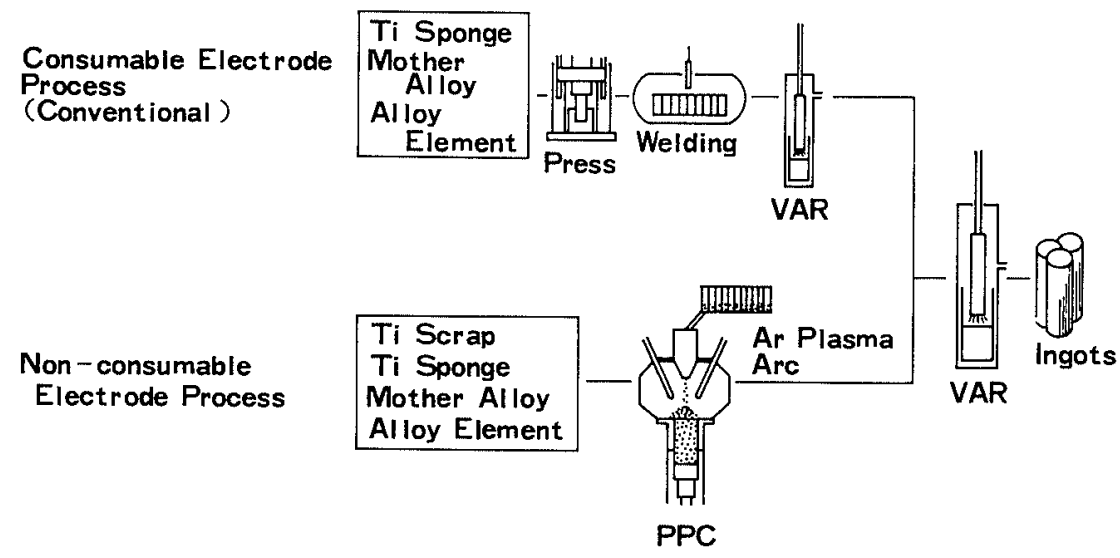

Fig. 1.

Comparison of titanium melting process 
is shown in Fig. 1 in comparison with the other existing processes. In this report the content of the operation of PPC-VAR process and the quality of ingots produced through this process are described.

\section{Outline of the Plasma Progressive Casting (PPC) Furnace}

PPC is a technology developed to melt titanium. It can melt materials continuously by plasma arc under inert atmosphere at atmospheric pressure, and to obtain progressively cast primary ingot by withdrawing the mold bottom plate continuously. The cross section of the furnace is shown in Fig. 2 and the specification of the furnace is shown in Table 1. As the plasma arc is of high temperature and has good directivity it is effective for the melting of refractory materials, such as titanium, because high temperature can be obtained by the thermal and magnetic pinching effects of plasma, which contributes to concentrate the plasma arc by the contraction of the arc column. And with the high arc directivity, troubles caused by mold wear are scarce.

Plasma arc in the PPC is generated between cathodes of 6 non consumable water cooled torches (tungsten) and titanium raw materials fed into the water cooled mold using argon gas and helium gas as media. Because the arc is effectively directed towards the (titanium) raw materials, the risk of explosion of the copper molds by

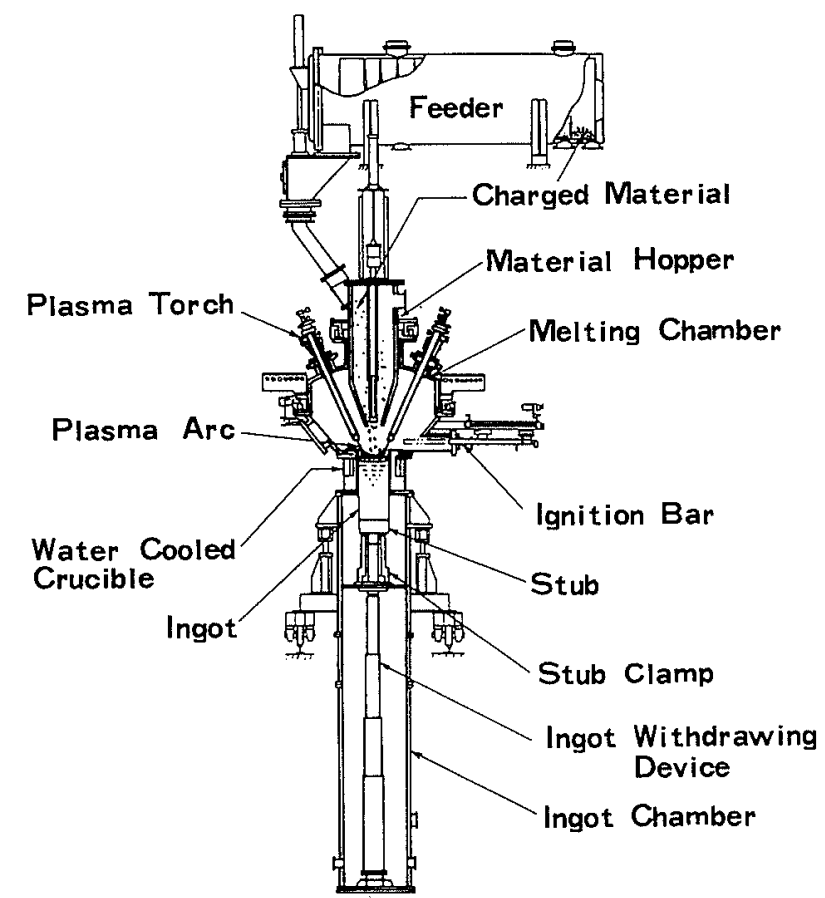

Fig. 2. Schematic diagram of 2 ton PPC furnace.

Table 1. Main specifications of 2 ton PPC

\begin{tabular}{ll}
\hline Plasma torch & 6 torches, rotating \\
Plasma power & $540 \mathrm{kWh}$ \\
Atmosphere & Ar $\left(1.0 \times 10^{2} \mathrm{kPa}=1 \mathrm{~atm}\right)$ \\
Charging material & Sponge Ti, Ti and Ti-alloy scrap, \\
& mother-alloy, etc. \\
Ingot size & $435 \mathrm{~mm} \phi, 355 \mathrm{~mm} \phi \times 3000 \mathrm{~mm}$ \\
Ingot weight & Max. $2000 \mathrm{~kg}$
\end{tabular}

water leakage is quite low. To reduce the attack of the mold and to obtain the homogeneous melt, six plasma torches system was adopted and the torches are rotated during the melting. For the adoption of the plural torches, it was required to design the torch to be compact. For that reason water cooled electrodes with tungsten tips were selected.

Raw materials are fed continuously into the water cooled mold from the dram feeder positioned on the top of the furnace accordingly to the progress of the melting, and melted by the plasma arc. In the bottom of the water cooled mold a starting block which can be pulled up and down is positioned and is drawn with the growth of the ingot. This starting block is used also as a stub in the later process of VAR.

The characteristics of the PPC process are as follows.

1) Melt and cast without contamination,

2) Limit of evaporation loss or variation of chemical composition,

3) Melting of refractory materials such as titanium,

4) Use of titanium scrap as raw material, and

5) Uniform and sound stacked cast structure.

\section{Operation of the PPC and the Quality of Ingots}

\subsection{Melting Efficiency (Melting $\mathrm{Ti} \mathrm{kg} / \mathrm{kWh}$ ) and the Density of Ingots Produced}

The characteristics of ingots produced by the PPC process is strongly affected by the input power $(\mathrm{kW})$ and melting speed (melting $\mathrm{Ti} \mathrm{kg} / \mathrm{min}$ ). The relation between apparent density of ingots and melting speed is shown in Fig. 3. The increase in the melting speed lowered apparent density of the ingot. When the input power is increased, the apparent density increases at same melting speed, however the effect of increasing of melting speed inclose on lowering the apparent density. As the result lowering of density is inevitable.

On the other hand, as shown in Fig. 4 the melting efficiency increases accordingly to the increase of the melting speed. From the view point of increasing the melting efficiency and namely for the reduction of the melting cost, higher melting speed is desirable. The density distrition of cross section of an ingot in Fig. 5 .

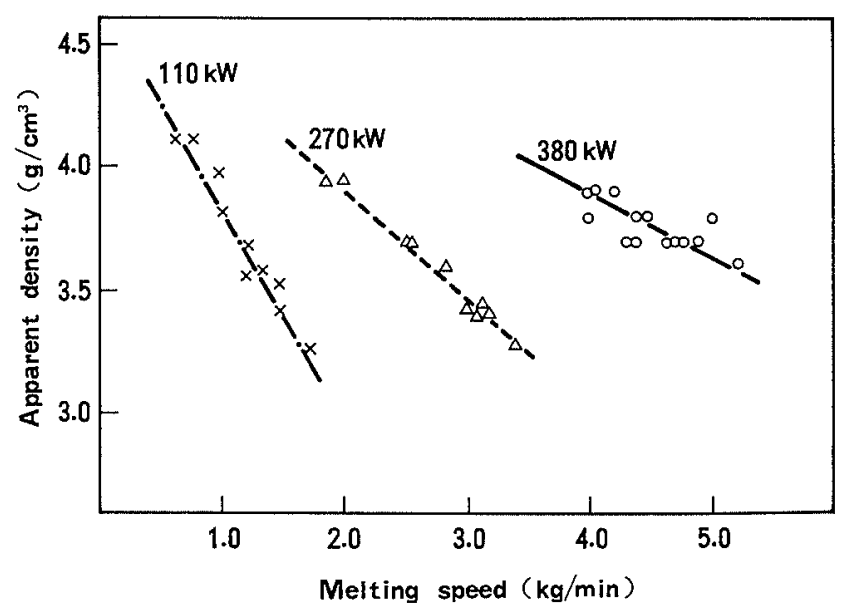

Fig. 3. Relation between the melting speed and the ingot density. 
The density of the ingot at the center is about 4.5 and close to the desnity of pure titanium, though it at the periphery of the ingot is comparatively low. At the periphery of the ingot, tianium scraps were remained partially unmelted. And also at the center part, pores were observed and pores precipitation of $\mathrm{MgCl}_{2}$, which might come from sponge titanium, was observed in the pores. It was considered that when the melting speed

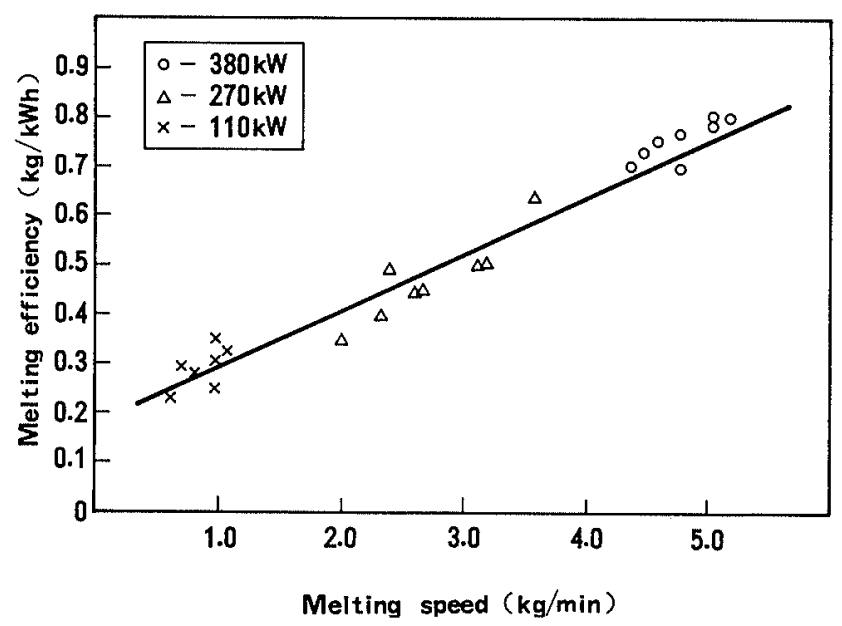

Fig. 4. Relation between the melting speed and the melting efficiency.

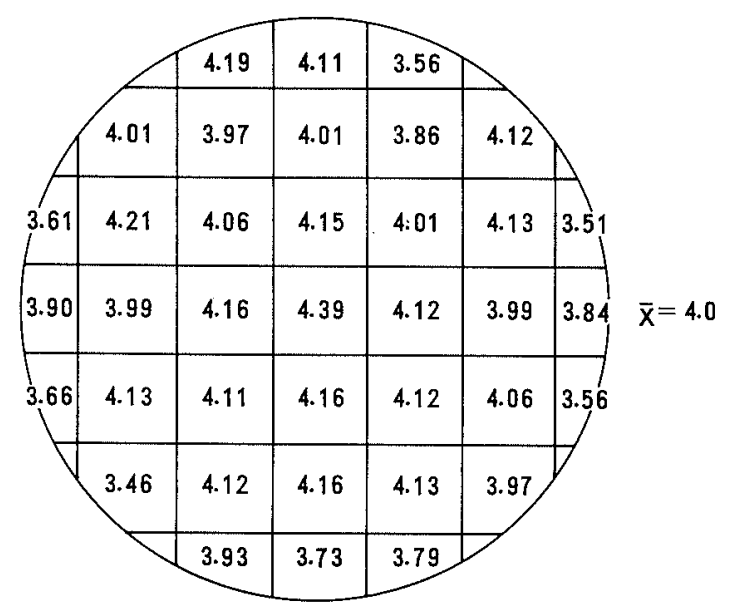

Fig. 5. Density distribution of a PPC titanium ingot. Melting power; $380 \mathrm{~kW}$, Melting speed; $4 \mathrm{~kg} / \mathrm{min}$, Sponge-Ti ratio; $50 \%$ was increased, adding to the increase of unmelted titanium scrap at periphery of ingot, release of $\mathrm{MgCl}_{2}$ was disturbed and so the apparent density was lowered.

The effect of the density of the PPC ingot which was used as VAR electrode on the VAR operation is shown in Fig. 6. According to the lowering of apparent density of PPC ingots, deterioration of the vacuum degree was observed. It is not clear whether such variation of vacuum degree will affect the quality of VAR ingot, but taking into consideration of the ingot quality, the vacuum degree is controlled below $1.33 \mathrm{~Pa}$ in Hoshizaki Plant. Then the maximum melting rate of PPC is limited to $5.0 \mathrm{~kg} / \mathrm{min}$ and then by this limitation the apparent density of higher than 3.5 can be assured.

\subsection{Relation between Electric Current Density and Electrode Tip Wearing}

As the cathode tip, $2 \% \mathrm{ThO}_{2}$ bearing tungsten is used to make the torch compact, because it is necessary to take certain countermeasures to avoid mixing of Heavy Density Inclusions (HDI), which can be caused by the wear of tungsten tip. A study has been carried out on the effect of cathode dimension and electric current density on the cathode wearing.

The results are shown in Fig. 7. For the cathode electrode diameter of 14 and $15 \mathrm{~mm} \phi$, the change of wearing rate by the increase of the current density has not been detected, however in case of $20 \mathrm{~mm} \phi$ elec-

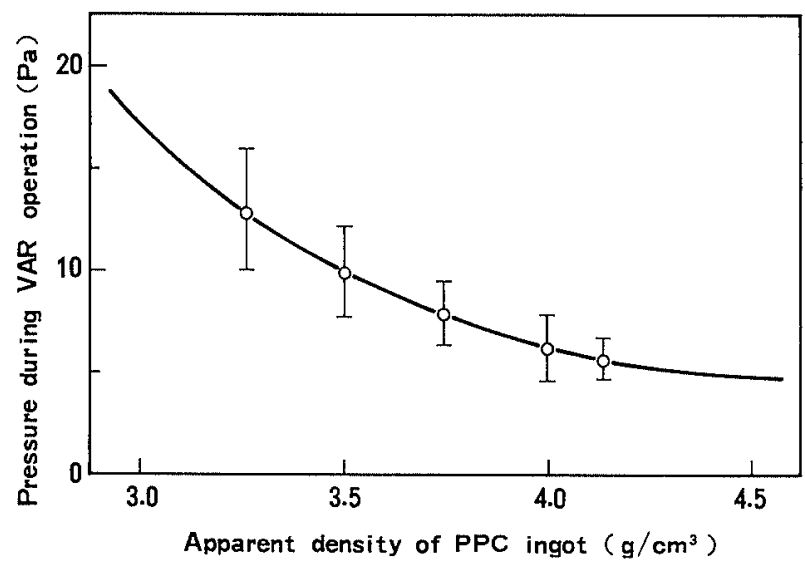

Fig. 6. Relation between the $\mathrm{PPC}$ ingot density and the pressure during VAR operation.
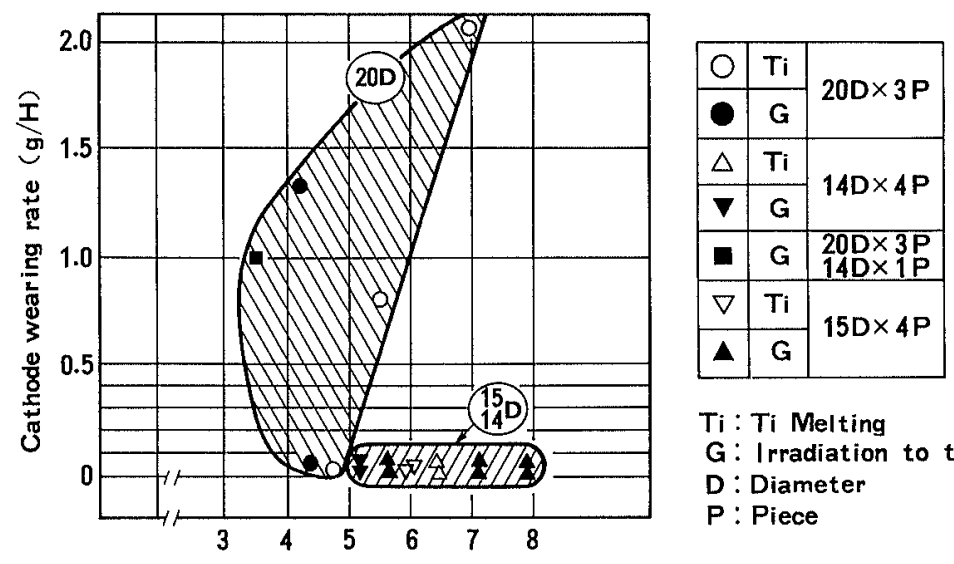

Ti : Ti Melting

G: I rradiation to the Graphite

D : Diameter

$P$ : Piece
Fig. 7.

Relation between the current density and the cathode wearing rate.

Current density of cathode $\left(A / \mathrm{mm}^{2}\right)$ 


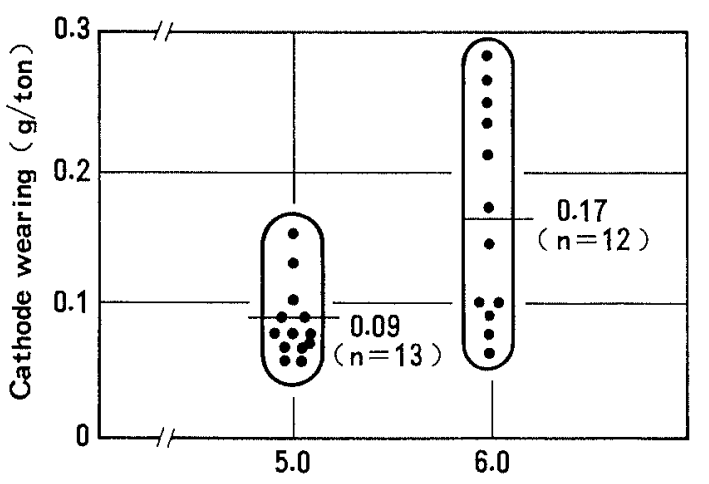

Current density of cathode $\left(\mathrm{A} / \mathrm{mm}^{2}\right)$ (Using $15 \mathrm{~mm} \phi$ electrode)

Fig. 8. Relation between the current density and the cathode $(15 \mathrm{~mm} \phi)$ wearing.

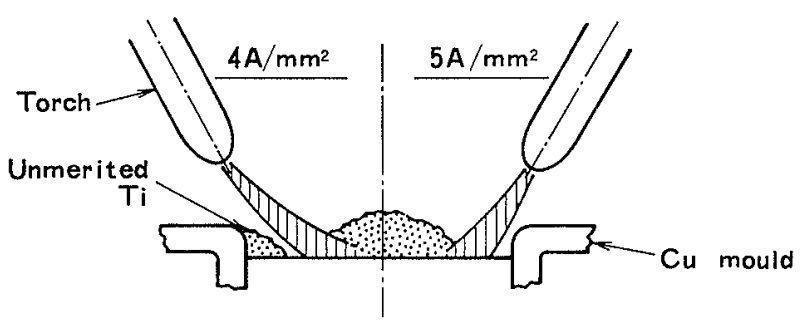

Fig. 9. A scrap melting

trode with the increase of the current density, the increase of the wearing rate has been observed. This is possibly caused by the lack of chilling ability by argon gas compared to the increasing of the heat generated. Chilling ability by argon gas depends on the space between electrode and torch nozzle under same gas flow condition.

Then the change in cathode wear has been checked by melting the titanium using the $15 \mathrm{~mm} \phi$ electrode varying the current density. The result is shown in Fig. 8. From the test it was confirmed that when the current density is reduced, the cathode wear decrease. When the current density is controlled under $4 \mathrm{~A} / \mathrm{mm}^{2}$, sound ingot can not be obtained as unmelted scrap at the periphery of the ingot increases. Taking into consideration the melting of the scrap, (shown in Fig. 9) and stabilization of cathode wearing, proper current density is decided as $5 \mathrm{~A} / \mathrm{mm}^{2}$. The temperature of the $\mathrm{W}$ $\mathrm{ThO}_{2}$ electrode tip was measured at an elevated current density of up to $75 \mathrm{~A} / \mathrm{mm}^{2}$ and it attained to $2760 \mathrm{~K}$. Theoretically melting of electrode tips in such temperature can not happen and the melting of electrode tip was not eventually observed.

In spite of the above facts, $0.01 \mathrm{~g} /$ melting Ti-ton of weight loss of the tips has been actually detected. The surface of the electrode tips are like shot blasted and has manifolds like marks of gas leaking. It is understood that small particles of tungsten or $\mathrm{ThO}_{2}$ sublimated. Therefore it is supposed that the worn particles in the ingot is not observed. For 10 years of experience in operation, HDI has never been detected by ultra sonic testing of billets nor of products.
Table 2. Main specifications of small PPC.

$\begin{array}{ll}\text { Plasma torch } & 3 \text { torches } \\ \text { Plasma power } & 300 \mathrm{~kW} \\ \text { Atomosphere } & \operatorname{Ar}\left(1.0 \times 1.0^{2} \mathrm{kPa}=1 \mathrm{~atm}\right) \\ \text { Ingot size } & 200 \mathrm{~mm} \phi \times 830 \mathrm{~mm} \\ \text { Ingot weight } & 100 \mathrm{~kg}\end{array}$

Table 3. Melting condition with Argon--Helium plasma.

\begin{tabular}{lll}
\hline & He gas addition ratio & $0,20,40 \%$ \\
Test 1 & Target material & SUS 403 \\
& Plasma current & $500-1100 \mathrm{~A} /$ torch $\times 3$ torches \\
& Arc length & $50 \mathrm{~mm}$ \\
& Plasma gas volume & $100 l /$ torch $\times 3$ torches \\
\hline \multirow{2}{*}{ Test 2 } & He gas addition ratio & $0,20,40,50 \%$ \\
& Target material & SUS 403 \\
& Plasma current & $1000 \mathrm{~A} /$ torch $\times 3$ torches \\
& Irradiation time & $3.5 \mathrm{~min}$ \\
& Arc length & $50 \mathrm{~mm}$ \\
& Plasma gas volume & $100 l /$ torch $\times 3$ torches \\
\hline
\end{tabular}

\subsection{Effect of Plasma Gas Species on the Arc Efficiency}

As described earlier, to increase the efficiency in plasma arc melting, it is required either to apply high input power input melting or to increase the heat efficiency of the arc itself. When the higher current is applied for rasing the input power, it increases the risk of cathode wear. Therefore the voltage has to be increased. As far as the direct current plasma arc is utilized, to rise the voltage it is necessary to increase the inclination of electric potential. Though argon gas had been generally used as plasma gas, the application of argon (Ar gas)-helium (He gas)-plasma was studied aiming at the improvement of the heat efficiency of plasma which might be caused by pinching effect.

To investigate the melting characteristics under $\mathrm{Ar}-$ He mixing gas plasma, melting tests of target materials (SUS 403) were carried out using a small PPC $(100 \mathrm{~kg})$ of the research laboratory of Daido. The specification of the furnace is shown in Table 2. Prior to the melting, the chamber was evacuated to vacuum $(13 \mathrm{~Pa})$, and re-pressurized to the atmospheric pressure by argon gas. From this condition, the melting test (Test 1 and Test 2), of which the conditions are shown in Table 3, were initiated. The relation between current and voltage with different gas contents is shown in Fig. 10. (Test 1). Increase of voltage according to the increase of $\mathrm{He}$ gas content is observed in the figure. The percentage of the increment is 5 to $15 \%$ in case of $20 \% \mathrm{He}$ gas addition and 15 to $20 \%$ with the addition of $40 \% \mathrm{He}$ gas. The effect of $\mathrm{He}$ gas addition becomes remarkable when the current is high. It is supposed that this is why the electrical resistivity of the plasma arc becomes higher because of the higher travel speed of the He molecular. (As the arc length was kept constant to $50 \mathrm{~mm}$ during the tests, it is resulted in the increase of the inclination of the electric potential by the He gas addition.) The melted area after $3.5 \mathrm{~min}$ of applying plasma arc on the target material with and without $\mathrm{He}$ gas are shown in Fig. 11 (Test 2). The volume of melted zone was cal- 
culated from the appearance of the cross section of the target materials in Fig. 11 (melted volume was calculated as the part of a sphere).

Arc efficiency power for melting/input power under various experimental conditions evaluated from the above mentioned volume were compared as shown in Table 4. Compared to the test with pure Ar gas, the arc efficiency were improved $40 \%$ by the addition of $20 \%$ $\mathrm{He}$, and $67 \%$ by the addition of $40 \% \mathrm{He}$ gas. As the increase of the arc efficiency by the addition of $\mathrm{He}$ gas

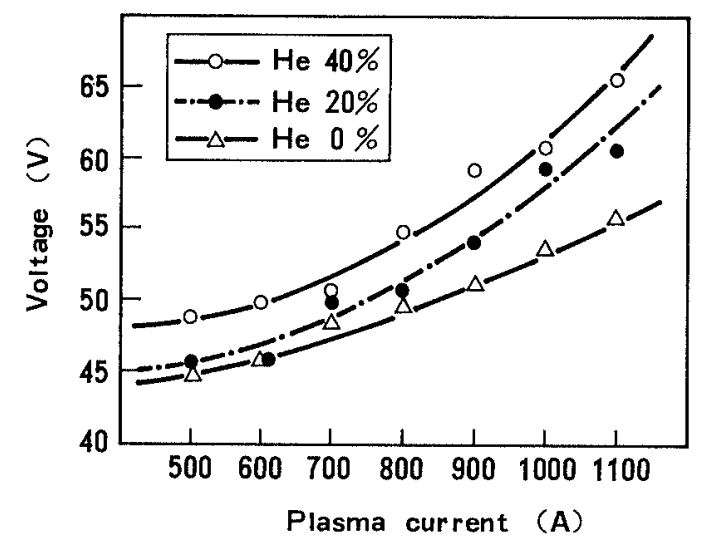

Fig. 10. Influence of the plasma gas on the voltage.

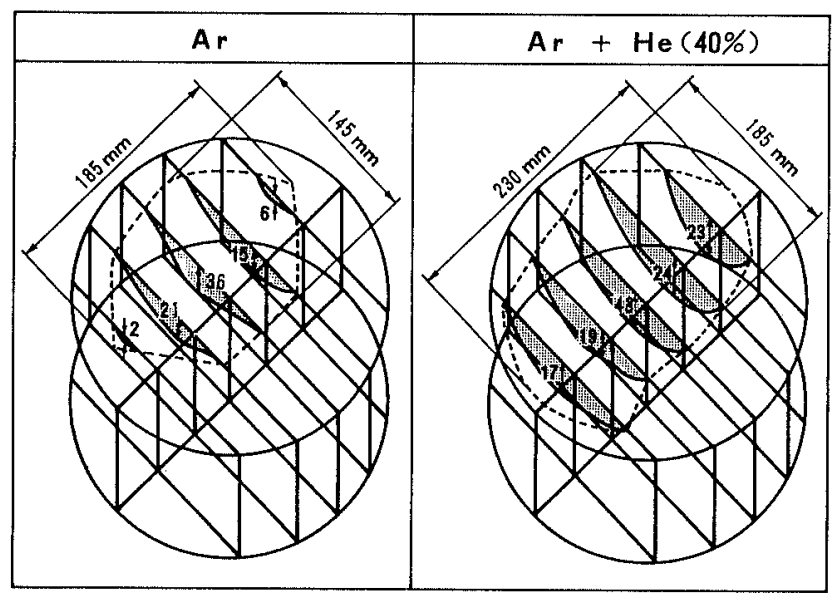

Fig. 11. Comparison of the target material condition after plasma irradiation with and without helium. in Ar plasma gas has been recognized, the heat efficient improvement by thermal pinch effect seems to be bigger than the effect of voltage rise. However, instability of The arc was observed when the He gas content exceeded $50 \%$. Explanation of the mechanism and countermeasure for such phenomena shall be studied from now on. $70 \%$ improvement of the arc efficiency by $40 \% \mathrm{He}$ gas addition, which is similar to the result obtained by the laboratory scale test, has been also obtained by a test done by the production furnace. On the current test the helium gas after used has been released in the air. Recovery of helium has to be considered from the economical point of view.

\subsection{Control of Chemical Composition}

The calculated content and the actual chemical analysis of the ingot is shown in Table $\mathbf{5}$ for the ingot after PPC-VAR process of which condition is that the mixing ratio of titanium scrap in the raw materials were varied from 50 to $100 \%$ and the rest was sponge titanium, is shown in Table 5. The analysis of the ingots after VAR were done with turning chips which were taken after removing the real surface of the ingots. As seen in the Table 5 the maximum increase of iron and oxygen content were $0.02 \%$ and the average of the increase were $0.015 \%$ for oxygen and $0.005 \%$ for iron. These are permissible level concerning the control of chemistry. As for the other elements, the satisfaction of ASTM GR2 has been confirmed.

In the actual operation, the mixing raio of titanium scrap is in the range of 50 to $70 \%$. To increase the mixing ratio beyond this, further recovery of good quality titanium scrap and establishment of pre-treat-

Table 4. Arc efficiency under various experimental condition.

\begin{tabular}{ccccc}
\hline & $\begin{array}{c}\text { Melted } \\
\text { volume } \\
\left(\mathrm{cm}^{3}\right)\end{array}$ & $\begin{array}{c}\text { Impot } \\
\text { power } \\
(\mathrm{kWh})\end{array}$ & $\begin{array}{c}\text { Power for } \\
\text { melting } \\
(\mathrm{kWh})\end{array}$ & $\begin{array}{c}\text { Arc } \\
\text { efficiency } \\
(\%)\end{array}$ \\
\hline $\mathrm{Ar}$ & 404 & 9.5 & 1.4 & 15 \\
$\mathrm{He}(20 \%)$ & 566 & 10.0 & 2.1 & 21 \\
$\mathrm{He}(40 \%)$ & 768 & 10.9 & 2.7 & 25 \\
\hline
\end{tabular}

Table 5. Behavior of chemical composition during PPC-VAR in case of different kind of scrap mixing.

\begin{tabular}{|c|c|c|c|c|c|c|c|c|c|}
\hline & & & \multicolumn{6}{|c|}{ Chemical composition (wt \%) } & \multirow{3}{*}{$\begin{array}{c}\text { Number } \\
\text { of } \\
\text { heats }\end{array}$} \\
\hline & \multicolumn{2}{|c|}{ Mixing ratio $(w t \%)$} & \multicolumn{2}{|c|}{ Charged content } & \multicolumn{2}{|c|}{ Ingot after PPC-VAR } & \multicolumn{2}{|c|}{ Increase during PPC-VAR } & \\
\hline & Sponge & Scrap & $\mathrm{O}$ & $\mathrm{Fe}$ & $\mathrm{o}$ & $\mathrm{Fe}$ & $\mathrm{O}$ & $\mathrm{Fe}$ & \\
\hline \multirow{3}{*}{ Plates } & 50 & 50 & 0.113 & 0.05 & 0.12 & 0.054 & 0.007 & 0.004 & 7 \\
\hline & 30 & 70 & 0.11 & 0.05 & 0.12 & 0.06 & 0.01 & 0.01 & 2 \\
\hline & 0 & 100 & 0.11 & 0.06 & 0.13 & 0.07 & 0.02 & 0.01 & 2 \\
\hline \multirow{2}{*}{ Pipes } & 50 & 50 & 0.11 & 0.05 & 0.12 & 0.05 & 0.01 & 0 & 2 \\
\hline & 30 & 70 & 0.11 & 0.05 & 0.12 & 0.05 & 0.01 & 0 & 1 \\
\hline \multirow{2}{*}{ Turnings } & 50 & 50 & 0.105 & 0.05 & 0.11 & 0.05 & 0.005 & 0 & 1 \\
\hline & 30 & 70 & 0.12 & 0.06 & 0.13 & 0.06 & 0.05 & 0 & 1 \\
\hline GR2 & \multicolumn{2}{|c|}{ Standard } & - & - & $\leq 0.25$ & $\leq 0.30$ & - & - & - \\
\hline
\end{tabular}


ment system of scrap, such as cutting and pickling of scrap are indispensable.

\section{Quality of PPC-VAR Melted Products}

Chemical composition at each part of 2 ton pure titanium ingot produced through the PPC-VAR process is shown in Fig. 12. The distribution of chemical composition of each element by position in the ingot is uniform and almost same level to that of the oridnary VAR double melted ingot. And concerning on the mechanical properties, satisfaction of the standards of ASTM GR2 and JIS GR2 was confirmed as shown in Fig. 13. Manufacturing process of test sample is as follows: PPC-VAR-Rolling (bar)-Heat treatment

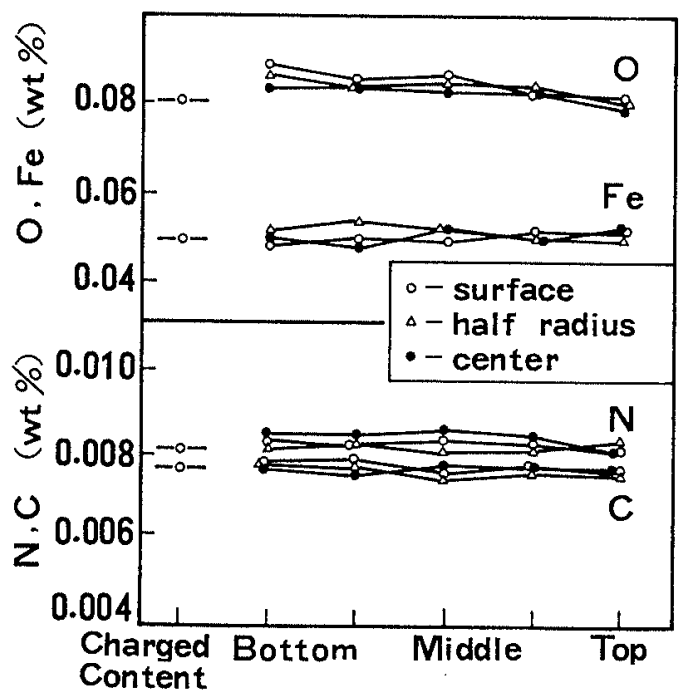

Fig. 12. Distribution of chemical compositions in a pure titanium ingot

Titanium scrap ratio; $50 \%$

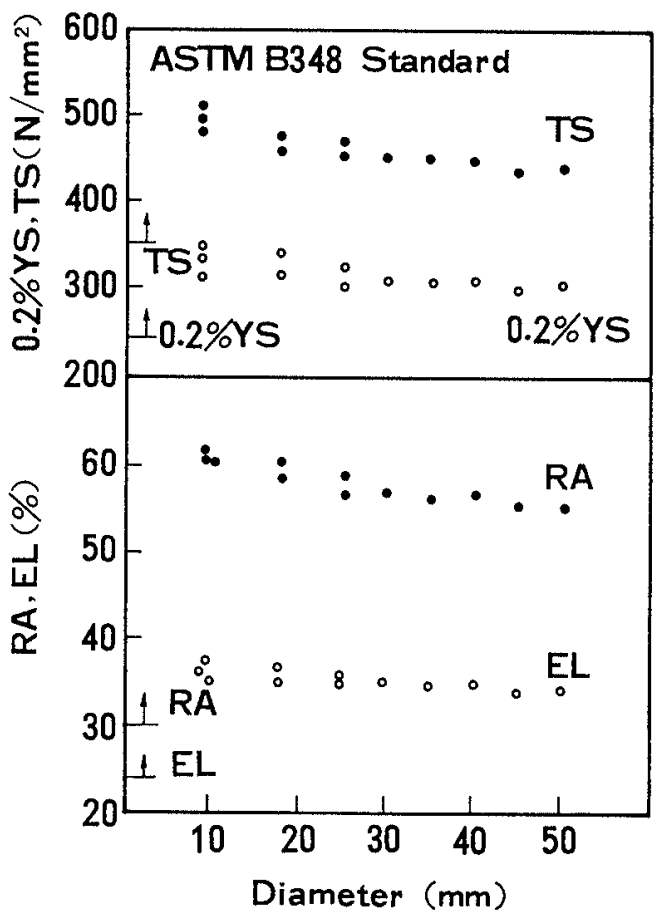

Fig. 13. Mechanical properties of a pure titanium bar. PPC-VAR-Rolling (bar)-Heat Treatment $\left(750 \times 1^{\text {h }}\right)$ $\left(750^{\circ} \mathrm{C} \times 1 \mathrm{~h}\right)$. One of the characteristics of titanium is its high resistance to corrosion, as shown in Fig. 14 similar properties to the referred material were obtained on JIS method corrosion test. Also by the ultra sonic inspection which is able to detect minimum $0.3 \mathrm{~mm}$ diameter inclusion of the products, defects by HDI has not been observed and the result was revealed to be satisfactory.

Chemical composition at each part of 2 ton $6 \% \mathrm{Al}$ $4 \% \mathrm{~V}$-titanium ingot produced through the PPCVAR process is shown in Fig. 15. The distribution of the chemical composition in the ingot was almost same level to that of the ordinary VAR double melted ingot, and chemical composition standard of AMS and ASTM were satisfied. The yield of each chemical element after PPC-VAR were, $98 \%$ for $\mathrm{Al}, 99 \%$ for $\mathrm{V}$, and $110 \%$ for oxygen, and constant. Though the increase of oxygen was observed through the whole process, it is still in controllable range and does not cause any problem in the process.
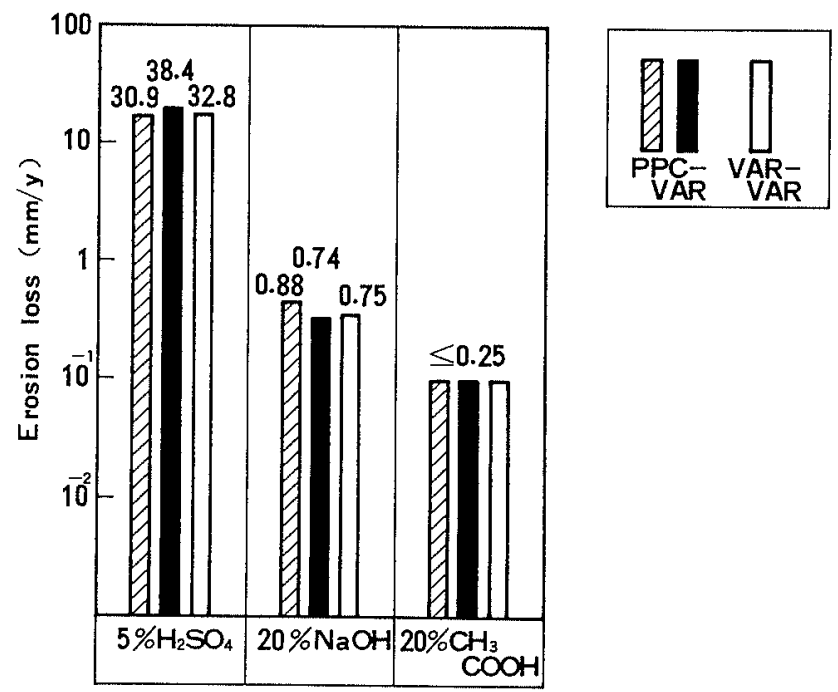

Fig. 14. Result of the erosion test (JIS method). PPC-VAR-Rolling (bar)-Heat Treatment $\left(750 \times 1^{\mathrm{h}}\right)$

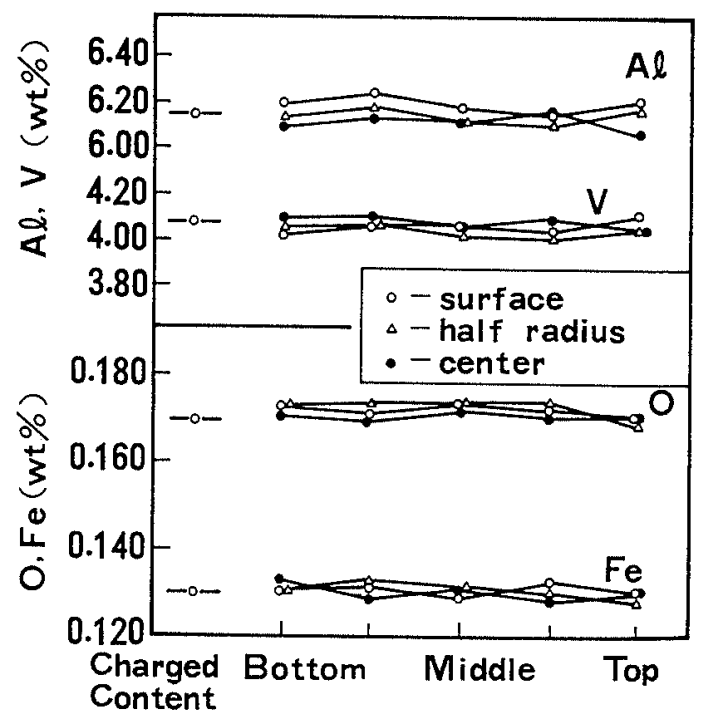

Fig. 15. Distribution of the chemical compositions in a Ti-6Al-4V ingot.

Titanium scrap ratio; $50 \%$. 
The mechanical properties of the material produced by the PPC-VAR process is shown in Fig. 16 and standards of ASTM and JIS are both satisfied. Both for pure titanium and titanium alloys any HDI by ultra sonic has not been detected. In view of this, American engine manufactures standard on HDI can be satisfied without problem, in spite of that the PPC process itself has not been approved as an appropriate process for aircraft application. As a matter of fact, we have been shipping the PPC-VAR melted materials already 10 years for the public application, and have never received any complain resulted in HDI.

\section{Automatic Operation of the PPC}

To control adequately the feeding of raw materials and the drawing of the mold correspondingly to the melting condition in the mold is necessary to achieve smooth continuous melting and casting using diverse titanium sources. Initially the control of feeding and withdrawing had been done manually, for which operators had been observing and evaluating the melting condition through monitor of inside the furnace. One heat lasts for about $7 \mathrm{~h}$, therefore the elimination of such exhausting job and the improvement of labor

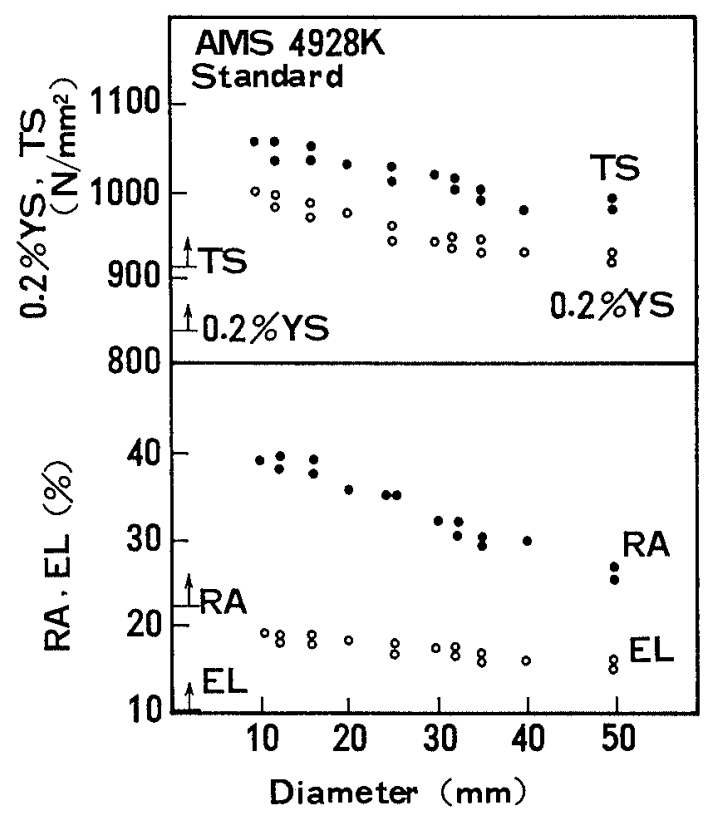

Fig. 16. Mechanical properties of a $\mathrm{Ti}-6 \mathrm{Al}-4 \mathrm{~V}$ bar. PPC-VAR-Rolling (bar)-Heat Treatment $\left(750 \times 1^{\text {h }}\right)$ productivity were the most urgent subjects to be solved. To solve this, treatment by the infrared thermal picture analysis system was introduced as a method to grasp the melting condition. With to the data processing of the informed thermal picture, melting status was converted into numerical data taking the average temperature of the melting spot as effective factors, and the feeding of raw materials were done proportional to such numerical value. At same time withdrawing of the mold was done automatically so as to keep the arc voltage constant. The result of such control is shown in Fig. 17. Far minute control compared to the manual control was performed and by that reduce of melting time by $5 \%$ was achieved by eliminating loss time during the process. And the operation without personnel was realized.

\section{Conclusion}

Melting of titanium by the PPC-VAR process were concluded as follows.

(1) Characteristics of the ingot produced by the PPC process were strongly affected by input power and melting speed. Though the apparent density of the ingot drops by the increase of melting speed, melting speed can be increased without apparent density lowering by raising the input power. Deterioration of vacuum degree of VAR was observed when the apparent density of the PPC ingot decreases. It is required to maintain the apparent density to higher than 3.5 to keep the pressure in chamber less than $1.5 \mathrm{~Pa}$. Melting speed of $5.0 \mathrm{~kg} / \mathrm{min}$ is considered as maximum at input power level of $380 \mathrm{kWh}$.

(2) The wear of electrode $\left(\mathrm{W}-\mathrm{ThO}_{2}\right)$ of the PPC plasma torch increased as the increase of electrical current density. In actual operation, selection of the current density in 5 to $6 \mathrm{~A} / \mathrm{min}^{2}$ is optimum considering the feature of melting. Principal mechanism of the wear of the electrodes is considered as by sublimation of tungsten or $\mathrm{ThO}_{2}$, and then the possibility of the mixing of HDI directly into the titanium bath is not feasible.

(3) Melting capacity is increased by the addition of $\mathrm{He}$ into Ar plasma gas. The effect of $\mathrm{He}$ addition is proportional to the percentage of $\mathrm{He}$ addition. When the $\mathrm{He}$ gas content exceeds $50 \%$, melting condition became quite unstable. The cause of this is not yet clear.

(4) Use of $100 \%$ titanium scrap is possible in PPC

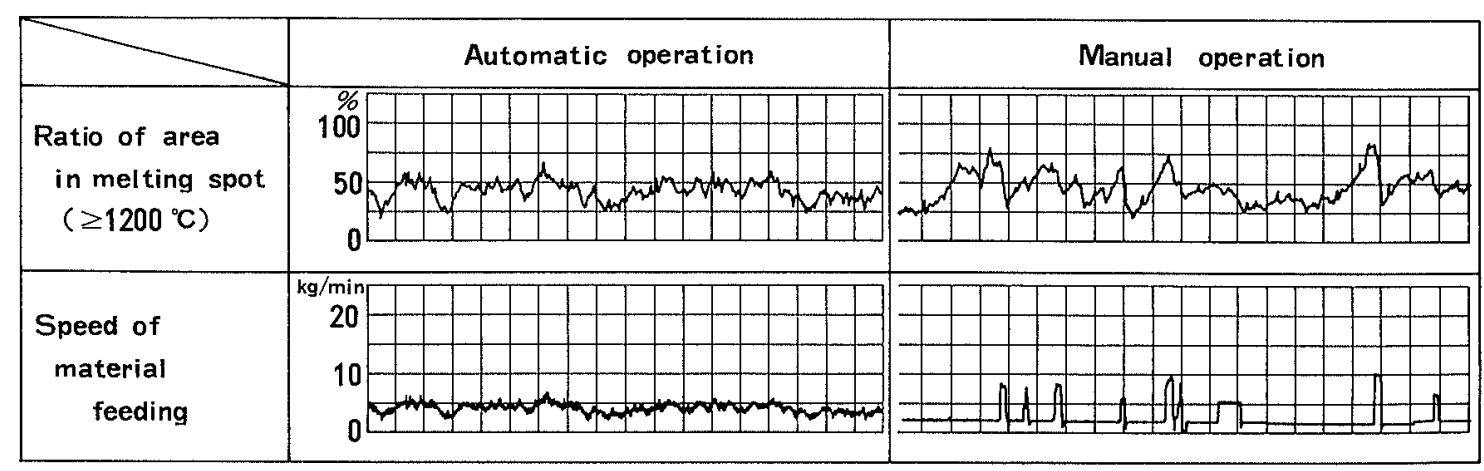

Fig. 17. Comparison of the material feeding control in the conventional and the automatic operation. 
melting operation.

(5) Compared to the products produced by the ordinal process of press formed electrode-VAR-VAR, similar quality has been confirmed in the material produced by PPC-VAR process as for chemical compsosition, mechanical properties, and resistivity to corrosion.

PPC developed by Daido Steel is an outstanding facility for the melting of titanium. Especially possibility to use up to $100 \%$ of titanium scrap is the strong point of the furnace. The process is effective for the melting of public used titanium or titanium alloys, of which market is growing, and outstanding as a recycling equipment of titanium scrap, which will be increased in future. Establishment of the system to recover titanium scrap and pre-treatment of titanium scrap are the subjects to be seriously attacked from now on.

\section{REFERENCES}

1) H. Yamada and T. Shimizu: Denki-Seiko (Electr. Furn. Steel), 54 (1983), 1.

2) K. Ando and M. Hasegawa: Phenomena of Welding Arc Sampo Co., Ltd., Tokyo, (1967). 